\title{
Resilience Processes, Engagement and Emotional Competencies, in Professionals Attending Elder People in Violence Situations in Saltillo, Coahuila and Monterrey, Nuevo León, Mexico
}

\author{
Procesos de Resiliencia, Engagement y Competencias Emocionales en \\ profesionales de atención a población adulta mayor en situaciones de \\ violencia en Saltillo, Coahuila y Monterrey, Nuevo León México
}

\author{
Laura Karina Castro Saucedo ${ }^{1}$ \\ Cesar Arnulfo De León Alvarado \\ Jesús Acevedo Alemán ${ }^{3}$ \\ Cesar Omar Ramírez Ríos ${ }^{4}$ \\ Universidad Autónoma de Coahuila, México
}

\begin{abstract}
In recent years, an increasing number of studies have investigated resilience, which is considered a phylogenetic process developed to increase survival (Stein, 2009; Aparecida dos Santos \& Nunes Moreira, 2014). Resilience is a construct that has been the topic of many studies. The objective of this investigation is to identify the relationship between the five dimensions of resilience in professionals who tend to elderly people, labor engagement and the emotional competencies. Several linear regression models were used to investigate the levels of prediction between the independent and dependent variables. The main results show relationships among resilience and its different dimensions, engagement $(\beta=.207 ; p=.005)$ and emotional competencies $(\beta=.710 ; p=.001)$ including four of its five dimensions on the analysis $\left(R^{2}=.724, F=108.63, g l=2, p=.001\right)$.
\end{abstract}

Keywords. Resilience, labor engagement, emotional competencies.

Resumen. En los últimos años se han incrementado los estudios sobre la resiliencia como un proceso desarrollado filogenéticamente para la supervivencia (Stein, 2009; Aparecida dos Santos \& Nunes Moreira, 2014). El objetivo de esta investigación fue identificar la relación existente entre las dimensiones de la resiliencia de profesionales que atienden adultos mayores y el engagement laboral y la relación con las competencias emocionales. Se elaboraron modelos de regresión lineal para establecer los niveles de predicción entre las variables independientes y dependiente. Los principales resultados arrojan una relación entre la resiliencia (así como sus diversas dimensiones), el engagement $(\beta=.207 ; p=.005)$ y las competencias emocionales $(\beta=.710 ; p=.001)$ incluyendo cuatro de las cinco dimensiones en el análisis $\left(R^{2}=.724, F=108.63, g l=2, p=.001\right)$.

Palabras clave. Resiliencia, engagement, competencias emocionales.

\footnotetext{
${ }^{1}$ Laura Karina Castro Saucedo.Universidad Autónoma de Coahuila, México. Dirección Postal: Avenida Dra. Cuquita Cepeda de Dávila s/n Col. Adolfo López Mateos C.P. 25125 Saltillo, Coahuila. Correo: karinacastros@gmail.com ${ }^{2}$ Cesar Arnulfo De León Alvarado. Universidad Autónoma de Coahuila, México. E-mail: cesar.leon@uadec.edu.mx ${ }_{3}^{3}$ Jesús Acevedo Alemán Daiane Folle. Universidad Autónoma de Coahuila. E-mail: jesusaceve@hotmail.com

${ }^{4}$ Cesar Omar Ramírez Ríos. Universidad Autónoma de Coahuila, México. E-mail: cesar.rmz.rios@hotmail.com
}

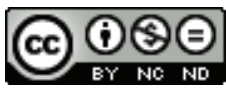

Esta obra está bajo una licencia de Creative Commons Reconocimiento-NoComercial-SinObraDerivada 4.0 Internacional. 


\section{Introduction}

Professionals who work with vulnerable populations currently face important challenges. New scenarios occur not only in society but also in the job environment, such as having to manage stressful situations, the accumulation of work, new problems requiring new interventions and personal life issues. According to the United Nations Educational, Scientific and Cultural Organization (UNESCO, 2015), education must prepare people and communities to face the tension caused by new changes worldwide along with the complexity and even contradiction among these changes. Leyton-Pavez, Valdés-Rubilar and Huerta-Riveros (2017) state that risky psychosocial situations in organizations are important factors that influence the occurrence of labor stress and mental and physiological diseases and have a negative impact of the life quality of people, their families and their environments. This permanent dynamic among these workers is also a professional and personal challenge, as these individuals are required to cope with not only with specific situations but also stress, emotional situations, the institutional demands of their work, situations that arise in different dimensions of life and the harmony among them. Thus, professionals must recognize their limitations to allow for the partial or total minimization of unnecessary stressors and, thus, the creation of skills and offer suggestions to improve their quality of life and professional performance (Brolese, Guedes dos Santos, da Silva Mendes, Santos da Cunha, \& Rodrigues, 2017).

Brolese et al. (2017) also suggest that resilience is an important factor allowing professionals to care for their own health, suggesting that resilience is involved in personal growth and the development of personal potential. For example, the development of self-esteem can contribute to resilience in social workers who have dealt with service users that experienced trauma-related events (Kapoulistsas \& Corcoran, 2015, p. 89). Salovey, Bedell, Detweiler and Mayer (1999) theorize that people with higher emotional intelligence (EI) cope better with the emotional demands of stressful encounters because they are able to "accurately perceive and appraise their emotions, know how and when to express their feelings, and can effectively regulate their mood states" (p. 160). In this research paper, the participants' narratives suggest that working with distressed patients is complex, and support from their job environment is important because it helps them achieve positive results. The relationship between a supportive work environment and its contribution to reductions in distress have also been previously described (Badger, Royse, \& Craig, 2008; Kapoulistsas, \& Corcoran, 2015).

Resilience is defined as the ability to overcome and thrive in the face of hardships, recover from stressful events or maintain equilibrium under significant threats (Smith, Dalen, Wiggins, Tooley, Christopher, \& Bernard, 2008) and recover from adversities by adopting positive coping strategies (De Caroli \& Sagone, 2016). All human beings have some degree

of resilience. Resilience is an innate resource that can also be acquired over time (Aparecida dos Santos \& Nunes Moreira, 2014).

Resilience allows people to adapt to adverse contexts and situations; identifying processes and conditions that are favorable to the development of resilience in professionals who attend elderly populations in situations of violence is therefore 
important and preventing their physical and psychosocial decline must be a priority (Suárez-Bagnasco, 2016).

Recent studies involving adult populations have found that resilience is negatively associated with neuroticism, and positively associated with extraversion, agreeableness and conscientiousness. However, no significant association with kindness was observed (for example, Campbell-Sills et al., 2006; Palma-García \& Hombrados-Mendieta, 2017). In other research on resilience factors, De Caroli and Sagone's (2016) results showed that the teenagers with whom they worked had higher mean scores on the dimensions of competency and engagement, and lower mean scores on the dimensions of adaptability and control. The same research reports that teenagers with profiles of self-realization had higher levels of resilience $(F=16,560 ; p=.001)$ and adaptability $(F=10,878 ; p=.001)$. It is important to recognize that in this investigation, engagement makes reference to a permanent state of energy and constant motivation at the time of doing labor activities, "a positive mental state of realization related to work, characterized by vigor, dedication and absortion” (López \& Moreno, 2013, p. 539).

According to the above definition, professionals who work with elderly people in situations of violence need to improve their resilience, engagement and emotional competencies to perform their job and care for their emotional and physical health. Recently, Cárdenas and Jaik (2014) identified new quantitative factors indicating that engagement is a generator of positive emotions, positive self-conception, social support and resilience in the workplace. Some of these and other elements are considered in research papers variables linked to engagement (Salanova \& Schaufeli, 2009). Conversely, Magnano, Craparo and Paolillo (2016) investigated the relationship among resilience, motivation and performance in the workplace among 488 Italian workers and found that emotional intelligence (EI), and particularly emotional competencies emerging from the analysis such as self-regulation and motivation, enabled the development of abilities that helped people adjust their actions to achieve individual, group and organizational goals.

According to the above studies, EI is considered an antecedent of resilience, and the results confirm that EI plays a significant role in resilience and motivation for achievement. Both emotional intelligence (EI) and emotional competencies encompass personality traits and behaviors that show knowledge and skills that can potentially facilitate individual achievement and positive work outcomes in areas such as job performance, career advancement, customer service, team work and leadership. Using competency models based on EI, this intelligence appears to be positively related to productive organizational outcomes (Froman, 2009). According to Armstrong, Galligan and Critchley (2011), EI may be directly connected to resilience because EI behaviors in stressful circumstances are adaptive. Armstrong et al. (2011) pointed out that EI is an antecedent to resilience rather than encompassing resilience, and that EI functions through its composite dimensions to facilitate resilience. Magnano, Craparo, \& Paolillo (2016) found a relationship between resilience and EI $\left(\beta=.42, R^{2}=.18, p=.001\right)$ and that employees with higher resilience and ability to cope with their emotions can be more motivated to reach goals, succeed and, in turn, show more satisfaction and creativity in the workplace. A study conducted by Sánchez and Robles (2014) examined data that showed 
the relationship between socio-demographic information, personality and resilience in a sample of 348 policemen from different police units in Spain. The authors found a strong association among emotional control $\left(r=.98 ; p=.01 ; \eta^{2}=.87\right.$; potency $\left.=.99\right)$ and impulse control $\left(r=.87 ; p=.01 ; \eta^{2}=.93\right.$; potency $\left.\left.=1.00\right)\right)$ and resilience. According to national and international research, controlling emotions and self-regulation abilities are personality characteristics that promote resilience in these professionals (Martinez-Arias \& De puelles-Casenave, 2010). Kapoulitsas and Corcoran (2014) examined stress predictors and resilience in social workers, and those with better development of "social and emotional competencies" (EI, reflexive capability, social competency and empathy) were also more resilient to stress (Kinman \& Grant, 2011). According to Pérez-Escoda, Bisquerra, Filella and Soldevila (2010), emotional competencies can be defined as the "body of knowledge, capacities, abilities and attitudes needed to comprehend, express and accurately regulate emotional phenomena". These authors also proposed the following 5-dimension theoretical model: emotional awareness, emotional regulation, emotional autonomy, social competency and competencies for life and wellness. These dimensions were also grouped into more specific competencies (Pérez-Escoda, Bisquerra, Filella, \& Soldevila, 2010). Bisquerra and Pérez (2007) performed another investigation and pointed to the necessity of approaching analyses of emotional competencies based on the construct of EI. EI is an essential element, integral to the development of capacities in life, and the dimension of emotional education is intimately connected to the construct of EI using an educational approach, even more so than the psychological approach.

Emotional competencies are important for the promotion of better adaptation to context and better coping with life's circumstances (Pérez-Escoda, Bisquerra, Filella, \& Soldevila, 2010). These authors also investigated a sample of 1537 people and validated the scale of Emotional Development for Adults (CDE-A), discovering a high correlation among the dimensions of regulation, social competencies and autonomy. Based on this perspective, the current article investigates engagement and emotional competencies and their link with the development of resilience (Sánchez \& Robles, 2014) in professionals who work with elderly people in situations of violence in Saltillo and Monterrey, Mexico.

Finally, this study also considers Connor and Davidson's (2003) approach to resilience in which the following 5-factor structure was obtained: (1) personal competency, self-exigencies and tenacity, (2) confidence in one's own intuition and tolerance towards adversity, (3) positive acceptance of change and establishing safe relations, (4) control and (5) spiritual influence.

Emotional competencies and engagement in the development of resilience. Resilience is situated in the positive psychology framework and can be understood as the ability to adapt (Luthar, Cicchetti \& Becker, 2000; Palma-García \& Hombrados-Mendieta, 2017; Kinman \& Grant, 2011; Kapoulitsas \& Corcoran, 2014) to internal or external stress in a flexible and ingenious way (Crowder \& Sears, 2016). Resilience is a complex construct that involves not only traits or personal capacities, but also the environmental and psychosocial factors that influence these capacities. Resilience is considered more of a process than a personality trait that can therefore be developed (Kapoulitsas \& Corcoran, 2014; Luthar, 1999; Luthar, Cicchetti, \& Becker, 2000; Fernandes de Araújo, Teva, \& Bermúdez, 2015). 
The development of resilience is important as a primary resource for the prevention of situations derived from stress and phenomena such as burnout and compassion fatigue, which are risk factors to which professionals are exposed as they work with vulnerable groups as follows: "It has been recognized that the recuperation capacity plays an important role in helping professionals deal with stress" (Kapoulistsas \& Corcoran, 2015, p. 89).

Thus, the development of emotional competencies may be a factor favoring the growth of resilience. According to an investigation of predictors of stress and resilience in social workers, those who showed highly developed "social and emotional competencies" are considered more resilient to stress (Kinman \& Grant, 2011). The highlighted social and emotional competencies included emotional intelligence, reflexive capacity, social competence and empathy (Kapoulistsas \& Corcoran, 2015).

According to a study conducted by Perez-Escoda, Bisquerra, Filella and Soldevila (2010), emotional competencies can be defined as "a set of knowledge, capacities, abilities and attitudes necessary to understand, express, and properly regulate emotional phenomena". These authors also proposed a theoretical model involving the following 5 dimensions: emotional conscience, emotional regulation, emotional autonomy, social competence, and competencies for life and wellness. These dimensions are also used to group competencies that are even more concrete (Pérez-Escoda, Bisquerra, Filella, \& Soldevila, 2010).

From the perspective of emotional intelligence, the development of emotional competencies is framed in the development of characteristics that favor the evolution of resilience, such as adaptability, tolerance, social responsibility, good humor, good self-esteem, self-discipline and self-control (Garmezy, Masten, \& Tellegen, 1984; Garmezy, 1991; Rutter, 1979, 1985; Werner \& Smith, 1992 cited by Palma-García \& Hombrados-Mendieta, 2017).

Furthermore, engagement is a permanent state of energy and constant motivation while performing work activities. Thus, engagement is "a positive mental state of realization related to work that is characterized by vigor, dedication and absorption" (Schufeli, Salanova, González-Roma, \& Bakker, 2002, p. 539).

According to Ten, Bakker, Hetland and Keulemans (2012), vigor represents the highest level of energy and resilience while working. This dedication is defined as staying focused at work and performing with enthusiasm and significance. Absorption is a state of concentration and happiness at work. These three characteristics counteract fatigue, cynicism and lack of personal efficiency, which are the main characteristics of burnout.

According to Maslach, Schaufeli and Leitner (2001), engagement is characterized by energy, significance and efficacy, which are the direct opposites of the following three dimensions of burnout (measured by the MBI-GS): fatigue, cynicism and lack of personal efficiency. Workers with high engagement scores have high energy and connection to their work and perceive themselves as capable of efficiently facing the different demands of their jobs. Engagement is not only a specific and temporal state but also a cognitive-affective state that becomes more persistent over time and is not focused on a specific object or behavior (Schaufeli et al., 2000 in Lisbona, Morales, \& Palací, 2009). 
Román, Battistelli and Odoardi (2013) describe their perspective of engagement in which engagement is valuable in understanding worker perceptions in an organization and, importantly, their attitudes in various complex contexts.

Thus, evaluating the perception of professionals who tend to vulnerable groups of their own work is important to help improve the development of resilience. This analysis could significantly contribute to facilitating work balance and avoiding fatigue, allowing employers to create a work environment and work processes that lead to feelings of enthusiasm and motivation among employees who perceive their jobs as "active" and "good" (Ten, Bakker, Hetland, \& Keulemans, 2012, p. 114). It is important to mention, however, that the current paper considers the investigation on resilience and their 5-factor structure, performed by Connor and Davidson (2003), as follows: (1) personal competence, self-demand and tenacity, (2) trust in their own intuition and tolerance to adversity, (3) positive acceptance of change and establishing safe relationships, (4) control and (5) spiritual influence. According to the aforementioned structure, these characteristics are included in this investigation because they could be related to emotional competencies and engagement in the development of resilience in professionals who work with vulnerable groups in Saltillo and Monterrey, Mexico. We hypothesized that resilience is positively related to emotional competencies and work engagement (Hyp. 1); tenacity is positively related to labor engagement and the dimensions of the emotional competencies (Hyp.2); self-confidence and tolerance are positively related to work engagement and the dimensions of the emotional competencies (Hyp. 3), adaptability and netting are positively related to work engagement and the dimensions of the emotional competencies (Hyp. 4), and control is positively related to work engagement and the dimensions of the emotional competencies (Hyp. 5).

\section{Method}

\section{Participants}

In total, 116 professionals, including 66 psychologists, 39 social workers and 2 criminologists, all between the ages of 20 and 53, with a mean age of 27 and a standard deviation of 6.2 years, participated in this study. The general context of the current research was two public government institutions that offer care services and attention to vulnerable groups and highlight attention to elderly people in situations of violence and negligence. The sample was obtained by convenience and consisted of professionals who offer care and have at least one year's experience working with groups in vulnerable situations. Because the sample represented a population of young professionals, most participants were single $(86 \%)$, only $9.3 \%$ of the participants were married, and the remaining participants were cohabiting $(2.8 \%)$ or divorced $(1.9 \%)$.

\section{Instruments}

Resilience Scale CD-RISC. This scale was adapted from the Spanish translation by MateuPérez, García-Renedo, Caballer-Miedes and Gil-Beltrán (2010) of the American Scale of 
Resilience (CD-RIISC) by Connor \& Davidson (2003), "Scale of Resilience of ConnorDavidson" (Connor-Davidson Resilience Scale, CD-RISC; Connor and Davidson, 2003). This scale comprises 25 items. The respondents indicate which of the statements have been true in their case in the prior month on a scale from 0 to 4 , where $0=$ "it hasn't been true at all" and $4=$ "true almost always". The total scores range from 0 to 100 , and higher scores indicate greater resilience. The original version has good properties with a Cronbach's alpha of .89 (general population) and a test-retest reliability of .87 (people with TAG and TEPT). The translation to Spanish was conducted by two members of the research team and supervised by a bilingual professional with a psychology degree. The original scale has the following 5-factor structure: (1) self-demand and tenacity, (2) trust in their own intuition and tolerance to adversity, (3) positive acceptance of change and establishing safe relationships, (4) control and (5) spiritual influence. However, four factors were validated for this paper, and spiritual influence was removed because it is a valid dimension for the population in this investigation. The other dimensions were labelled differently for practical management.

The four dimensions and their items are as follows: (1) Tenacity: I always exert effort without caring about the result; I believe that I can achieve my objectives, even if there are obstacles; I do not give up even when things seem not to have a solution; I do not get discouraged easily with failure; I believe that I am a strong person when facing challenges and difficulties in life; I like challenges; I work to achieve my objectives without caring about the difficulties I find on the way; and I'm proud of my achievements; 2) I trust and have tolerance toward adversity; I try to see the fun side of things when I face problems; facing difficulties can make me stronger; when under pressure, I focus and think clearly; I prefer trying to solve issues by myself than letting others to make all the decisions; I can make unpopular or difficult decisions that affect other people if necessary; I'm capable of coping with unpleasant and painful feelings, such as sadness, fear and anger; and when I face problems in life, sometimes I act according to my feelings without knowing why, 3) Adaptability and Netting: I'm capable of adapting to changes; I have at least one intimate and safe relationship that helps me when I am stressed; I can face anything; the successful achievements of my past give me trust to face new challenges and difficulties; and I have a tendency to recover soon after illness, wounds or other privations, and 4) Control: During stress/crisis moments, I know where to find help; I clearly know what I want in life; and I feel that I control my life.

In this research, 17 items from the original scale were validated; $49.52 \%$ of the variance was explained, and the reliability coefficient was .909. The internal validity and reliability of each of the dimensions were good; the explained variance ranged from $53.19 \%$ to $79.93 \%$, and Cronbach's alpha reliability coefficients ranged from .736 and .833.

Engagement scale. The Utrecht Work Engagement Scale (UWES) was used in the version with the 17 items (Schaufeli, Salanova, González-Romá \& Bakker, 2002). Originally, the UWES had 24 items, including nine items related to vigor and 8 items related to dedication, and most of which included phrases from the MBI rewritten in a positive direction. For example: "when I wake up in the morning, I want to go to work" (vigor) versus "I feel fatigued when I wake up in the morning and have to go to work (emotional fatigue)" and 
"I am enthusiastic about my job" (dedication) versus "I have become less enthusiastic about my job" (cynicism). These reformulated items from the MBI were replaced by items related to vigor and original dedication, and new items related to absorption were added to constitute the UWES - 24. After a psychometric evaluation in two different samples of employees and students, 7 items were inconsistent and subsequently eliminated, and only the following 17 items remained: 6 items related to vigor, 5 items related to dedication and 6 items related to absorption (Schaufeli, Salanova, González-Romá, \& Bakker, 2002). This 17 -item version of the UWES is included in the appendix. In the subsequent psychometric analysis, two inconsistent items (Ab06 and VI 06) were identified; thus, some studies used a 15-item version of the UWES (Demerouti, Bakker, Janssen, \& Schaufeli, 2001). The analyzed data in this article include both the UWES - 15 and the UWES - 17 (see sections 4.1 and 5.1). The psychometric analysis of the UWES included factorial validity. The confirmatory factor analysis showed that the hypothetical structure of the UWES had three factors and is, thus, superior to the model with one factor and adjusted to data from different samples in Holland, Spain and Portugal (Schaufeli, Bakker \& Salanova, 2006). However, there is an exception. Using a factorial exploratory analysis, Sonnentag (2003) did not find a well-defined tri-factorial structure and used the total points on the UWES as a measure of engagement at work. We also examined their internal correlation. Even though the confirmatory factor analysis indicated a tridimensional structure, these three dimensions are intimately related; thus, we used the total score in the analyses in this study. Importantly, 14 items on the original scale were validated with $48.79 \%$ variance explained and a reliability coefficient of .90 .

Emotional Competence Scale (De León \& Ramírez, 2016).This scale was developed by De León and Ramírez (2016) following statements in a Spanish review by Bisquerra and Perez (2007) regarding the 5 emotional competencies that compose this construct. In this scale, 35 items were designed, revised by experts and preliminarily applied several times with acceptable levels of validity and reliability. In this study, acceptable scores were obtained on the general scale of Emotional Competencies, with $43.88 \%$ of the variance explained and a Cronbach's alpha reliability coefficient of .94.

Overall, 27 items were validated using an exploratory factorial analysis with factor loadings higher than .40, and the following 5 dimensions were identified: 1) Emotional regulation: I know how to calm down when I'm very sad or very angry; when I am angry, I'm aware of how I am going to react; I am capable of being calm even when I'm angry; I correctly express my emotions when I do not agree with something; and I enjoy my current life, 2) Emotional autonomy: I face current challenges positively; I regularly collaborate on activities by my own initiative; I am capable of giving with generosity without expecting anything in return; I show with my posture that I'm paying attention when I speak with somebody; and generally, I act according to my ideas and my values, 3) Social competence: I am capable of acting to prevent conflict; I am capable of regulating anger in others; I am capable of defending my rights when I feel that they aren't being respected; I pay attention to the people who I talk to; I am capable of deciding by myself without giving up to pressure from other people; I can spontaneously express my emotions; and I express my emotions without being repressed, 4) Competencies for life and wellness: I actively 
contribute to my family's wellness; I reach the goals that I set for myself; I generate a harmonious environment with my family; I am capable of generating a harmonious environment in my workplace; I live positively with the people to whom I relate; I assume the consequences of the decisions that I make in my current life; I enjoy the activities that I like the most with the people I love; and I recognize when it is necessary to ask for help, and 5) Emotional Conscience: I am capable of clearly naming my emotions; I clearly identify how I feel; and I can clearly name my emotions.

These dimensions had acceptable validity and reliability levels; the explained variances determined by the exploratory factorial analysis ranged from $44.82 \%$ to $56.78 \%$, the factor loadings were higher than .4 and the Cronbach's alpha reliability coefficients ranged from .785 to .846 .

\section{Procedures}

A lineal regression analysis was conducted to explore the elements related to resilience among professionals who tend to a vulnerable elderly population. The data were analyzed with the Statistical Package for the Social Sciences (SPSS, 21 version), and several multiple linear regression models were performed using steps with input criteria of $F=.05$ and .10 for elimination, excluding cases based on the adjustment list. The experiments were performed with the explicit awareness and written consent of all participants. A limitation of this research is the size and type of the sample, which is not representative; thus, the results can be applied only to the sample population. Another limitation is the proportion of different professions included in the sample.

\section{Results}

The descriptive characteristics of the three constructs measured in this study, including the mean (M), total population $(\eta)$, standard deviation $(S D)$ and Cronbach's alpha coefficients $(\alpha)$ of each scale and their subscales and correlations, are shown in table 1 . The three constructs of engagement, total resilience and total emotional competencies had the highest reliability coefficients $(\mathrm{ENG}=.90$; REST $=90$; CET $=.94)$. Of these three constructs, the resilience scale had a lower standard deviation $(S D=8.8)$ and mean score $(M=77.1)$ than the engagement scale $(M=53.2 ; S D=7.7)$ and total Emotional Competencies $(M=$ 98.1; $S D=12)$. We then described the correlations between engagement, total resilience, tenacity, self-confidence, tolerance to adversity, adaptability, netting, control, total emotional competencies, emotional regulation, emotional autonomy, emotional awareness, social competencies and competencies for life and wellness. Engagement was highly positively related to most of these variables. However, its highest correlation was with the total emotional competencies $(r=.722 ; p<.001)$, particularly with the dimension of emotional regulation $(r=.666 ; p<.001)$. Total resilience was also highly positively related to most variables, specifically to the total emotional competencies $(r=.829 ; p<.001)$, the dimension of emotional autonomy $(r=.749 ; p<.001)$, and the competencies for life and wellness $(r=.718 ; p<.001)$. The four dimensions of resilience analyzed were positively related to the total emotional competencies and each of its dimensions, except for adaptability and netting, and had the highest correlation within it $(r=.808 ; p<.001)$, as well as a high correlation with the competencies for life and wellness was observed $(r=.768 ; p<.001)$. 


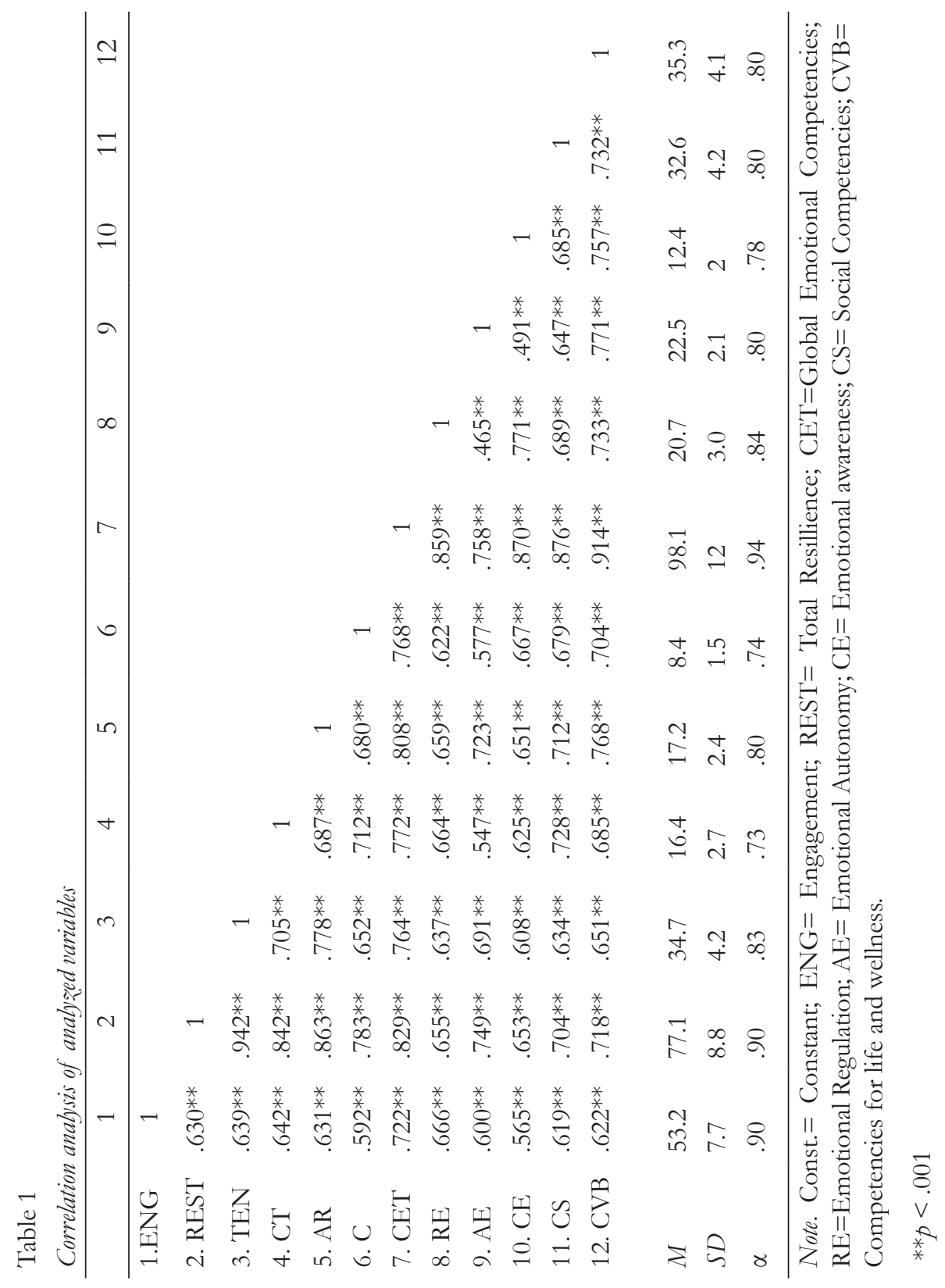

Actualidades en Psicología, 32(125), 2018, 33-50 
In the following section, a regression analysis is used to determine which constructs better predict resilience among social work professionals who work with groups of elderly people and investigate the assumptions of the first and second hypotheses. Five linear regression models were developed: the first model establishes the relationship among resilience, the engagement variables, and general emotional competencies; the direct and significant influence of engagement $(\beta=.207, t=2.868 ; p<.005)$ and emotional competencies $(\beta=.710, t=9.855 ; p<.001)$ on resilience was identified. The relationship between the constructs was significant $\left(R^{2}=.724, F=108,73, g l=2, p<.001\right)$ and the global emotional competencies were the greatest predictive force. Therefore, emotional competencies such as emotional autonomy, emotional awareness, emotional regulation, competencies for life and wellness and social competencies are the most predictive variables of resilience. However, commitment, dedication and vigor in the workplace, which are representative characteristics of engagement, play a smaller but significant role in the development of resilience (see table 2).

According to the above results, resilience emerges as a capacity that allows caregivers to adapt or professionals to deal with elderly people in situations of emotional stress, anxiety or depression (Menezes de Lucena, Fernández, Hernández, Ramos, \& Contador, 2006). Based on this first finding, the following linear regression models establish relationships among the dimensions of the total resilience scale and global emotional competencies scale. These models consider the entire engagement scale based on a discussion by its authors who did not find a well-defined tri-factorial structure, and a higher adjustment of the total score is required as an issue in the measurement of engagement in the workplace (Sonnentag, 2003). The second linear regression model indicates that a direct and significant relationship exists between tenacity, which is a part of resilience, and engagement $(\beta=.350$, $t=2.685, p<.01)$, and the emotional autonomy dimension of the emotional competencies $(\beta=.334, t=2.235, p=.031)$ These two independent variables are the only related variables in this model $\left(R^{2}=.657, g l=6, F=13.72, p<.000\right)$ (see table 1$)$.

This finding shows that emotional autonomy and work engagement are important aspects of resilience and its dimension of tenacity. Emotional autonomy, including its components of personal self-management, self-esteem, positive attitude toward life, responsibility, capacity to critically analyze social norms, capacity to ask for help and resources, and emotional self-efficiency (Bisquerra \& Pérez, 2007), and the relationship between these characteristics and energy to work, dedication and commitment in the workplace promote the development of tenacity in professionals who tend to vulnerable populations in social risk situations, such as elderly people. A relationship between resilience and self-efficiency was shown because overcoming adversity is an experience that modifies beliefs of selfefficiency to exercise self-control in life (Bandura, 2008).

The third model explores the relationship between the dimensions of self-confidence and tolerance to adversity and resilience as a dependent variable, and these independent variables have established and maintained predictive relationship with engagement $(\beta=.203, t=2.181, p=.032)$ and the dimension of social competencies $(\beta=.353$, 
$t=3.392, p<.001)$. The relationship among the variables in this model establishes that considering both social components results in a better prediction, i.e., confidence and tolerance toward adversity are mostly predicted by the construct of social competence, which involves the capacity to maintain good relationships with other people, the capacity to master social abilities and use accurate communication strategies when assertiveness and emotional expression play an essential role (Bisquerra \& Pérez, 2007).

Most of these qualities improve confidence and tolerance toward adverse situations as dimensions of professional resilience among social workers who attend to vulnerable groups. However, in this model, the presence of work commitment, dedication and energy from the engagement perspective also predicts self-confidence and tolerance toward adversity in a smaller but still direct and significant effect $\left(R^{2}=.618, g l=6, F=\right.$ $21,83, p<.000$ ) (see table 2).

Thus, self-confidence and tolerance toward adversity are components of resilience, suggesting that the social control of socio-emotional requirements and adverse situations are external and derive from interactions with other people, such that social competencies reinforce control elements and tolerance toward adverse situations in professionals who offer these services. However, several authors have described the process by which people transition from being completely alien to their work context to be an integrated worker (Cooper-Thomas \& Anderson, 2005).

The fourth linear regression model uses the dimension of adaptability and netting as a dependent variable and investigates its relationship with the emotional competencies and engagement. The direct and significant effect of social competencies $(\beta=.198, t$ $=1.991, p=.049)$ and competencies for life and wellness $(\beta=.423, t=3.75, p<.001)$ was observed. The construct of engagement and the other dimensions of the socioemotional competencies did not show any relationship with adaptability and netting even though the model was significant and had greater predictive ability than the previous model $\left(R^{2}=.649, g l=6, F=28,09 ; p<.001\right)$.

This model shows a more dynamic relationship when predicting adaptability and netting that counteracted the tolerance to adverse situations when linked to separate components of the social competencies and competencies for life and wellness. These elements better predict this characteristic of resilience, suggesting that more accurate and responsible behaviors, decision making, active citizenship, satisfaction with professional, personal and social life (Bisquerra \& Perez, 2007), and higher adaptability and netting predict more positive acceptance of change and better and safer relationships in facing adverse situations in the workplace or personal issues. Thus, this model shows the relevance of the elements of wellness in facing daily life challenges. Finally, the relationships established in the fifth linear regression model among engagement, the dimensions of the emotional competencies and the control component of resilience show similar behavior as those in the previous model, and the influence on social competencies $(\beta=.229, t=2.129, p=$ $.036)$ and competencies for life and wellness $(\beta=260 ; t=2.134 ; p=.036)$. were retained. Engagement was not related to resilience in this dimension. 
Table 2

Model of lineal regression of the dimensions of resilience, engagements and the dimensions of emotional competencies

\begin{tabular}{|c|c|c|c|c|c|c|c|c|c|}
\hline \multirow{2}{*}{$\begin{array}{l}\begin{array}{l}\text { Dimensions } \\
\text { of Resilience }\end{array} \\
\text { Model } 1\end{array}$} & \multirow{2}{*}{$\begin{array}{l}\begin{array}{l}\text { Predictory } \\
\text { variables }\end{array} \\
\text { Const. }\end{array}$} & \multirow{2}{*}{$\begin{array}{c}B \\
-2.439\end{array}$} & \multirow{2}{*}{$\begin{array}{c}\text { Typical } \\
\text { Error }\end{array}$} & \multirow[t]{2}{*}{$\beta$} & \multirow{2}{*}{$\begin{array}{c}t \\
-0.451\end{array}$} & \multirow{2}{*}{$\frac{p}{.653}$} & \multicolumn{2}{|c|}{$\begin{array}{l}95 \% \text { Confidence } \\
\text { interval } \\
\end{array}$} & \multirow{2}{*}{$\begin{array}{l}R^{2} \\
.724\end{array}$} \\
\hline & & & & & & & -13.2 & 8.322 & \\
\hline \multirow{2}{*}{$\begin{array}{l}\text { Total } \\
\text { Resilience }\end{array}$} & CEG & 0.659 & 0.067 & 0.71 & 9.855 & .000 & 0.526 & 0.792 & \\
\hline & ENG & 0.27 & 0.094 & 0.207 & 2.868 & .005 & 0.083 & 0.458 & \\
\hline Modelo 2 & Const. & -0.746 & 4.628 & & -0.161 & .873 & -10.08 & 8.587 & .657 \\
\hline \multirow[t]{6}{*}{ Tenacity } & ENG & 0.196 & 0.073 & $0.350^{*}$ & 2.685 & .01 & 0.049 & 0.343 & \\
\hline & $\mathrm{RE}$ & 0.028 & 0.219 & 0.018 & 0.126 & .90 & -0.414 & 0.469 & \\
\hline & $\mathrm{AE}$ & 0.66 & 0.295 & $0.334^{*}$ & 2.235 & .031 & 0.064 & 1.255 & \\
\hline & CE & 0.335 & 0.287 & 0.159 & 1.167 & .25 & -0.244 & 0.914 & \\
\hline & CS & -0.053 & 0.167 & -0.044 & -0.317 & .753 & -0.39 & 0.284 & \\
\hline & CVB & 0.211 & 0.219 & 0.155 & 0.962 & .341 & -0.231 & 0.653 & \\
\hline Model 3 & Const. & -3.281 & 2.609 & & -1.257 & .212 & -8.463 & 1.902 & .618 \\
\hline \multirow{6}{*}{$\begin{array}{l}\text { Self-confidence } \\
\text { and tolerance }\end{array}$} & ENG & 0.075 & 0.034 & $0.203^{*}$ & 2.181 & .032 & 0.007 & 0.143 & \\
\hline & $\mathrm{RE}$ & 0.118 & 0.107 & 0.131 & 1.104 & .272 & -0.094 & 0.33 & \\
\hline & $\mathrm{AE}$ & 0.048 & 0.13 & 0.028 & 0.372 & .711 & -0.209 & 0.306 & \\
\hline & CE & 0.039 & 0.154 & 0.029 & 0.255 & .799 & -0.267 & 0.345 & \\
\hline & CS & 0.231 & 0.068 & $0.353^{*}$ & 3.392 & .001 & 0.096 & 0.367 & \\
\hline & CVB & 0.117 & 0.08 & 0.172 & 1.463 & .147 & -0.042 & 0.275 & \\
\hline Model 4 & Const. & -2.334 & 2.174 & & -1.073 & .286 & -6.653 & 1.985 & .649 \\
\hline \multirow{6}{*}{$\begin{array}{l}\text { Adaptability } \\
\text { and Netting }\end{array}$} & ENG & 0.049 & 0.029 & 0.152 & 1.705 & .092 & -0.008 & 0.105 & \\
\hline & $\mathrm{RE}$ & 0.014 & 0.089 & 0.018 & 0.16 & .873 & -0.163 & 0.191 & \\
\hline & $\mathrm{AE}$ & 0.145 & 0.108 & 0.096 & 1.34 & .183 & -0.07 & 0.36 & \\
\hline & $\mathrm{CE}$ & 0.072 & 0.128 & 0.062 & 0.56 & .577 & -0.183 & 0.327 & \\
\hline & CS & 0.113 & 0.057 & $0.198^{*}$ & 1.991 & .049 & 0 & 0.226 & \\
\hline & CVB & 0.25 & 0.067 & $0.423^{*}$ & 3.75 & .000 & 0.117 & 0.382 & \\
\hline Model 5 & Const. & -2.815 & 1.514 & & -1.859 & .066 & -5.821 & 0.192 & .591 \\
\hline \multirow[t]{6}{*}{ Control } & ENG & 0.032 & 0.02 & 0.154 & 1.6 & .113 & -0.008 & 0.071 & \\
\hline & $\mathrm{RE}$ & -0.009 & 0.062 & -0.017 & -0.138 & .891 & -0.132 & 0.115 & \\
\hline & $\mathrm{AE}$ & 0.064 & 0.075 & 0.066 & 0.851 & .397 & -0.085 & 0.214 & \\
\hline & CE & 0.163 & 0.089 & 0.218 & 1.827 & .071 & -0.014 & 0.341 & \\
\hline & CS & 0.084 & 0.04 & $0.229 *$ & 2.129 & .036 & 0.006 & 0.163 & \\
\hline & CVB & 0.099 & 0.046 & $0.260^{*}$ & 2.134 & .036 & 0.007 & 0.191 & \\
\hline
\end{tabular}

Note. Const. $=$ Constant ENG $=$ Engagement REST $=$ Total Resillience; CET $=$ Global Emotional Competencies; $\mathrm{RE}=$ Emotional Regulation; $\mathrm{AE}=$ Emotional Autonomy; $\mathrm{CE}=$ Emotional awareness; $\mathrm{CS}=$ Social Competencies $\mathrm{CVB}=$ Competencies for life and wellness. $* p<.05$ 
Therefore, responsible and accurate behaviors, decision making, satisfaction with professional, personal and social life, good relationships with other people, mastery of social abilities and accurate communication strategies (Bisquerra \& Pérez, 2007) mostly predict control, which involves attitudes towards stress and life projects and control of life (Connor, \& Davidson, 2003) among professionals who attend to elderly populations (see table 2).

\section{Conclusions and Discussion}

We conclude that this investigation strongly supports the contributions by Kapoulistsas and Corcoran (2015), Brolese, Guedes dos Santos, da Silva Mendes, Santos da Cunha and Rodrigues (2017), De Caroli and Sangone (2016), Cárdenas and Jaik (2014), and Sánchez and Robles (2014), who emphasized the relevance and relationships among resilience, emotional components and work motivation or work engagement.

Hypothesis 1 regarding the relationship between resilience among professionals who tend to groups in social risk or vulnerable situations and emotional competencies and work engagement is supported, and according to the different regression models, work engagement and emotional competencies broadly predict resilience and its dimensions (Kapoulitsas \& Corcoran, 2014; De Caroli, \& Sangone, 2016; Cárdenas \& Jaik, 2014).

Hypotheses 2 and 3 are supported, as the tenacity and self-confidence dimensions of resilience are both related to engagement. However, the only competencies related to tenacity are emotional autonomy (Brolese, Guedes dos Santos, da Silva Mendes, Santos da Cunha, \& Rodrigues, 2017) and personal development (Magnano, Craparo, \& Paolillo, 2016), which are strongly correlated with individual and work progress based on effective management of EI, suggesting that coping with emotions allows for effective coping with adversity. We conclude from this investigation that individual-level training related to autonomy, self-concept and personal development could enable the conditions necessary for tenacity in coping with complex situations in daily life. However, the self-confidence and tolerance dimensions are mostly predicted by the emotional competencies and engagement. We therefore inferred that labor commitment and good relationships with other people are conditions necessary for developing self-confidence and tolerance, which allow for better coping with difficult or unstable situations. These results strongly agree with a study conducted by Kapoulitsas and Corcoran (2014), who found relationships among social competencies, EI, reflexive capability, social competency and empathy and resilience, and indicate that these relationships in work environments and the social support dimensions of empathy and social competency are relevant to professionals who tend populations in contexts of social risk or violence.

Finally, Hypotheses 4 and 5 are rejected because the dimensions of adaptability, netting, and control were not related to engagement and were related only to the components of socially oriented competencies and competencies for life and wellness. This finding is closer to the perspective of social support and resilience by Cárdenas and Jaik (2014) and the social control of impulses and emotions proposed by Sánchez and Robles (2014) and MartinezArias and De Puelles-Casenave (2011). This finding is related to the dimension of control being revised in this investigation. According to the results obtained in this study, studying the 
interactions among resilience, emotional competencies and engagement could be important in the determination of the development of abilities to cope with the work adversities facing professionals who tend to vulnerable groups, especially elderly people, who demand strong personal attention with high personal content and emotional significance.

\section{References}

Aparecida dos Santos, R., \& Nunes Moreira, M. C. (2014). Resilience and death: the nursing professional in the care of children and adolescents with life-limiting illnesses. Ciência \& Saúde Coletiva, 19(12), 4869-4878. doi: 10.1590/1413812320141912.18862013

Armstrong, A. R., Galligan, R. F., \& Critchley, C. R. (2011). Emotional Intelligence and Psychological Resilience to Negative Life Events. Personality and Individual Differences, 51(3), 331-336. doi: 10.1016/j.paid.2011.03.025

Badger K. Royse, D. \& Craig C (2008) Hospital social workers and indirect trauma exposure: An exploratory study of contributing factors. Health and Social Work 33(1), 63-72. doi:10.1093/hsw/33.1.63

Bandura, A. (2008). An agentic perspective on positive psychology. In S.J. Lopez (Ed.). Positive psychology: Exploring the best in people. (pp.167-196). Westport, CT: Greenwood.

Bisquerra, R. \& Pérez, N. (2007). The emotional competencies. Education XXI, 10, 61-82. doi: 10.5944/educxx1.1.10.297

Brolese, D., Guedes dos Santos, J., da Silva Mendes, J., Santos da Cunha, K., \& Rodrigues, J. (2017). Resilience of the health team in caring for people with mental disorders in a psychiatric hospital. Revista da Escola de Enfermagem da USP, 51, 1-8. doi: 10.1590/s1980-220x2016026003230

Campbell-Sills, L., Cohan, L.S., \& Stein, M.B. (2006). Relationship of Resilience to Personality, Coping and Psychiatric Symptoms in Young Adults. Behaviour Research and Therapy, 44, 585-599. doi: 10.1016/j.brat.2005.05.001

Cárdenas, T, \& Jaik, A. (2014). Inventario para la medición del Engagement (ilusión por el trabajo). Un estudio instrumental. Psicogente, 17(32), 294-306. doi: 10.17081/ psico.17.32.457

Connor, K. M., \& Davidson, J. R. T. (2003). Development of a new resilience scale: the Connor-Davidson Resilience Scale (CD-RISC). Depression and Anxiety, 18, 71-82. doi: 10.1002/da.10113

Cooper-Thomas, H. \& Anderson, N. (2005). Organizational socialization: a field study into socialization success and rate. International Journal of Selection and Assessment, 13, 116-128.

Actualidades en Psicología, 32(125), 2018, 33-50 
Crowder, R., \& Sears, A. (2016). Building resilience in social workers: An exploratory study on the impacts of a mindfulness- based intervention. Australian Social Work, 70(1),1-25. doi: 10.1080/0312407x.2016.1203965

De Caroli, M. E., \& Sagone, E. (2016). Resilience and psychological well-being: differences for affective profiles in italian middle and late adolescents. International Journal of Developmental and Educational Psychology 1(1), 149-159. doi: 10.17060/ijodaep.2016.n1.v1.237

De León, C. \& Ramírez, C. (2016). Emotional competencies of parents or guardians from the perspective of the tutors. (Unpublished thesis). UADEC, Mexico.

Demerouti, E., Bakker, A. B., Janssen, P. P. M., \& Schaufeli, W. B. (2001). Burnout and engagement at work as a function of demands and control. Scandinavian Journal of Work, Environment \& Health, 27, 279-286.

Fernandes de Araújo, L., Teva, I., \& amp; Bermúdez, M. D. (2015). Adult resilience; A theoretical revision. Psychological therapy, 33(3), 257-276. doi: 10.4067/s071848082015000300009

Froman, L. (2009). Positive Psychology in the Workplace. Journal of Adult Development, 17(2), 59-69. doi: 10.1007/s10804-009-9080-0

Garmezy, N. (1991) Resiliency and Vulnerability to Adverse Developmental Outcome Associated with Poverty. American Behavioral Scientist, 34, 416-430. doi: 10.1177/0002764291034004003

Garmezy, N., Masten, A. S., \& Tellegen, A. (1984). The study of stress and competence in children: a building block for developmental psychopathology. Child development, 55(1), 97-111. DOI: 10.1111/j.1467-8624.1984.tb00276.x

Kapoulitsas, M., \& Corcoran, T. (2015). Compassion fatigue and resilience: A qualitative analysis of social work practice. Qualitative Social Work, 14(I), 86-101.

Kinman, G., \&amp; Grant, L. (2011). Exploring stress resilience in trainee social workers: The role of emotional and social competencies. British Journal of Social Work, 41, 261-275. doi:10.1177/1473325014528526

Leyton-Pavez, C., Valdés-Rubilar, S., \& Huerta-Riveros, P. (2017). Methodology for the prevention and intervention of psychosocial risks at work in the public health sector. Journal of Public Health, 19(1), 10-16. doi: 10.15446/rsap.v19n1.49265

Lisbona, A., Morales, J. F., \& amp; Palací, F. J. (2009). The engagement as a result of the organizational socialization. International Journal of Psychology and Psychological Therapy, 9 (1), 89-100. Retrieved from: http://www.redalyc.org/pdf/560/56012876007.pdf

López, L., \& amp; Moreno, J. (2013). The coaching process as protectionary of engagement. Tourism \& Management Studies, 2, 536-550.

Luthar, S. (1999). Poverty and children's adjustment. Newbury Park, CA: Sage Publications.

Luthar, S. S., Cicchetti, D. \& B. Becker (2000). The Structure of Resilience, a Critical Evaluation and Guideline for Future Reports. Child Development, 71(3), 543-62. 
Magnano, P., Craparo, G., \& Paolillo, A. (2016). Resilience and Emotional Intelligence: which role in achievement motivation. International Journal of Psychological Research, 22(3), 39-54. doi: 10.21500/20112084.2096

Martínez-Arias, R., \& De Puelles-Casenave, C. (2010). Job emotional exigence in Units of Police Intervention. Clinical, Legal and Forensics Psychopathology, 10, 91-128. Recovered from http://masterforense.com/pdf/2010/2010art6.pdf

Maslach, C., Schaufeli, W. B., \& amp; Leitner, M. P. (2001). Job burnout. Annual Review of of Psychology, 52, 397-422. doi: 10.1146/annurev.psych.52.1.397

Masten, A. S., \& amp; Reed, M. G. J. (2002). Resilience in Development. In C. R. Snyder \& S. J. Lopez (Eds.), Handbook of Positive Psychology (pp. 74-88). New York: Oxford University Press. Recovered from: https://experts.umn.edu/en/publications/ resilience-in-development-3

Mateu Pérez, R., García Renedo, M., Gil Beltrán, J. M. And Caballer Miedes, A. (2010). The importance of teachers as guides or tutors of resilience. I European Congress of Resilience. Retrieved from: http://resilienciabarcelona.net/wp-content/ uploads/2010/10/com.-la-importanciade-los-docentes.pdf

Menezes de Lucena, V., Fernández, B. Hernández L. Ramos, F. Contador, I. (2006). Resilience and the Burnout Engagement model in formal caregivers of the elderly. Psicothema, 18(4), 791-796.

Palma-García, M. D., \& Hombrados-Mendieta, I. (2017). Resilience and personality in social work students and social workers. International Social Work, 60(I), 19-31. doi: $10.1177 / 0020872814537856$

Pérez-Escoda, N., Bisquerra, R., Filella, G., \& Soldevila, A. (2010). Construction of the questionnaire about emotional development in adults. (QDE-A). REOP, 21(2), 367-379. doi: 10.5944/reop.vol.21.num.2.2010.11539

Román, J. P., Battistelli, A., \& Odoardi, C. (2013). Work Engagement as Mediator between Perceived Participation, Supervisor Support and Altruistic Behaviors: Empirical Results from the Italian Social Enterprise Sector. Universitas Psychologica, 12(3), 899- 909. doi: 10.11144/javeriana.upsy12-3.wemp

Rutter, M. (1979). Maternal deprivation. Child Development, 50, 283-305. doi: $10.2307 / 1129404$

Rutter, M. (1985). Resilience in the face of adversity. Protective factors and resistance to psychiatric disorder. The British Journal of Psychiatry, 147(6) 598-611. doi:10.1192/ bjp.147.6.598

Salanova, M. \& Schaufeli, W. (2009). The Engagement in the Work. España: Alianza Ed.

Salovey, P., Bedell, B. T., Detweiler, J. B., \& Mayer, J. D. (1999). Coping intelligently: Emotional intelligence and the coping process. In C.R. Snyder (Ed.), Coping: The psychology of what works (pp. 141-164). New York: Oxford Press. doi: 10.1093/me d:psych/9780195119343.003.0007 
Sánchez, D., \& Robles, M. A. (2014). Personality and resilience in a special force corp of the National Police of Spain. Journal of Work and Organizational Psychology, 30(2), 75-81. doi:10.1016/j.rpto.2014.06.003

Schaufeli, W. B., \& Van Dierendonck, D. (2001). Utrechtse Burnout Schaal (UBOS) [Utrecht Burnout Scale]. De Psycholoog, 36, 9-12. doi: 10.1037/t05561-000

Schaufeli, W. B., Bakker, A. B., \& Salanova, M. (2006). The measurement of work engagement with a brief questionnaire: A cross-national study. Educational and Psychological Measurement, 66, 701-716. doi:10.1177/0013164405282471

Schaufeli, W. B., Salanova, M., González-Romá, V., \& Bakker, A. B. (2002). The measurement of engagement and burnout: A two sample confirmatory factor analytic approach. Journal of Happiness Studies, 3, 71-92.

Slattery SM, \& Goodman L A. (2009). Secondary traumatic stress among domestic violence advocates: Workplace risk and protective factors. Violence Against Women, 15(11): 1358-379. doi: 10.1177/1077801209347469

Smith B.W., Dalen J., Wiggins K., Tooley E., Christopher P., \& Bernard J. (2008). The Brief Resilience Scale: Assessing the ability to bounce back. International Journal of Behavioral Medicine, 15(3), 194-200. doi:10.1080/10705500802222972

Sonnentag, S. (2003). Recovery, work engagement, and proactive behavior (2003): A new Look at the interface between non-work and work. Journal of Applied Psychology, $88,518-528$.

Stein, D. J. (2009). The Psychobiology of Resilience. CNS Spectrum, 14(2), 41-47. doi: $10.1017 / \mathrm{s} 1092852900027280$

Suárez-Bagnasco, M. (2016). Resilience and executive dysfunction in healthy adults between 30 and 60 years old. Panamerican Journal of Neuropsychology, 14(4), 317-321. doi: $10.5604 / 17307503.1225266$

Ten Brummelhuis, L., Bakker, A. Hetland, J., \& Keulemans L. (2012). Do new ways of Working foster work engagement? Psicothema, 24(1), 113-20. Retrieved from: https://www.ncbi.nlm.nih.gov/pubmed/22269373

UNESCO .(2015). Rethinking Education. Towards a global common good? Paris: UNESCO. Retrieved from: http://unesdoc.unesco.org/ images/0023/002325/232555e.pdf

Recibido: 26 de febrero de 2018

Aceptado: 03 de mayo de 2018 